\title{
Folic acid awareness and intake among women in areas with high prevalence of neural tube defects in China: a cross-sectional study
}

\author{
Ziqian Zeng ${ }^{1,2}$, Ping Yuan ${ }^{1}$, Yanping Wang ${ }^{2}$, Xi Ma ${ }^{3}$ and Jun Zhu ${ }^{2, *}$ \\ 'Department of Epidemiology, West China School of Public Health, Sichuan University, Chengdu, People's \\ Republic of China: ${ }^{2}$ National Center for Birth Defects Monitoring of China, West China Women's and Children's \\ Hospital, Sichuan University, no. 17, Section 3, South Ren Min Road, Chengdu 610041, People's Republic of \\ China: ${ }^{3}$ Shanxi Provincial Maternal and Child Hospital, People's Republic of China
}

Submitted 29 July 2010: Accepted 9 January 2011: First published online 16 February 2011

\begin{abstract}
Objective: To measure folic acid awareness and intake rates among women of childbearing age in certain areas of China with a high prevalence of neural tube defects (NTD).

Design: A cross-sectional survey was carried out utilising a nineteen-item questionnaire enquiring into individual women's knowledge of, attitude towards and practice of folic acid supplementation.

Setting: A total of 293 low-income counties in six provinces of China.

Subjects: Women aged 19-44 years from six provinces with a high prevalence of NTD recruited from June to August 2008.

Results: Among 33025 participants, $57 \%$ had heard of folic acid but only 15\% knew all of the core information. The intake rate was $12 \%$; only $8 \%$ took the recommended dose and only $4 \%$ of non-pregnant women took folic acid. Some women did not take folic acid because they did not know that they should take it (49\%) or they had misconceptions about it (24\%). According to logistic regression analysis, rural residence was a risk factor for folic acid awareness. Ethnicity, educational level, average annual income per person and pregnancy were the influencing factors of folic acid awareness and folic acid intake.

Conclusions: Although more than half of the respondents had heard of folic acid, the intake rate was still very low in areas with a high prevalence of NTD. Thus, more efforts are needed to increase folic acid awareness and intake among women of reproductive age in these areas.
\end{abstract}

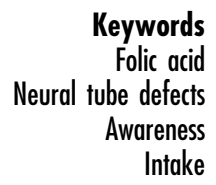

Neural tube defects (NTD), one of the most serious birth defects in the world, can lead to stillbirth, infant death and disability. Some studies confirmed that folic acid $(400 \mu \mathrm{g} / \mathrm{d})$ lowers the risk of NTD if women use it before and during early pregnancy ${ }^{(1,2)}$. Folic acid reduces the risk of NTD by 50-70\% and prevents other major birth defects $^{(3)}$. Since the 1990s, many developed countries have widely promoted folic acid supplementation for childbearing women as a public health measure against $\mathrm{NTD}^{(4-6)}$. Moreover, some developed countries started promoting food fortification ${ }^{(7,8)}$, particularly in 2006, when WHO released a guide on folate fortification to promote folic acid supplement use in all countries ${ }^{(9)}$.

Folic acid awareness and intake rates are important factors to be considered when evaluating the preventive effects of folic acid supplementation on NTD. In the past 10 years, many studies have reported folic acid awareness and intake rates in different counties, regions or populations ${ }^{(10-12)}$. For example, the March of Dimes Foundation's surveys in the USA have provided annual trends in folic acid awareness and behaviour ${ }^{(13)}$. Relevant studies were conducted in 2002 and 2007 in Japan to determine the awareness rate among laywomen ${ }^{(14)}$. Although most studies focused on women's folic acid awareness or intake rates, they did not deeply analyse differences in intake rates between women with partial knowledge and those with complete knowledge. Furthermore, the reasons for women not taking folic acid have not been sufficiently identified.

Previous studies identified that the prevalence of NTD in the northern areas of China is among the highest in the world ${ }^{(16,17)}$ - about 6 per 1000 live births involved NTD in northern rural areas in $1997^{(15)}$. Since 2008, although the prevalence of NTD had decreased because of some interventions, monitoring of national birth defects showed that the average prevalence of NTD in 
northern rural areas of China was about 3 per 1000 births. The surveillance is hospital based and covers pregnancies of $\geq 28$-week gestation.

A study in Shan Xi Province of northern China showed that about $10 \cdot 2 \%$ of women had ever used folic acid and only $3 \cdot 3 \%$ used it periconceptionally ${ }^{(18)}$. However, the study was conducted only in four counties from one province in northern China in 2005, hence necessitating further research to obtain more evidence before intervention. The objective of the present study was to obtain data regarding folic acid awareness and intake rates through different characteristics and knowledge points in northern China. Meanwhile, the reasons some women did not take folic acid have also been further analysed. Scientific evidence should be obtained to aid in the formulation of more effective intervention measures among public health decision makers working in areas with high occurrence of NTD.

\section{Methods}

The present study was conducted in 293 low-income counties of six provinces in northern China. The six provinces are Shann Xi, Shan Xi, Qing Hai, Xin Jiang, Gan Su and Inner Mongolia; a very high occurrence of NTD has been recorded in these provinces.

Women who went to local maternal and children's hospitals for prenatal examinations or pre-pregnancy care from June to August 2008 were selected as subjects. In the present study, a woman was considered eligible if she was 19-44 years old, had resided locally for $>1$ year and had no history of NTD-affected pregnancy.

The self-administered questionnaires were constructed on the basis of relevant literature and recommendations from experts. After conducting pilot tests and revisions of the initial questionnaire, the final questionnaire included a total of nineteen questions. Of these, six questions were with regard to demographic characteristics, eight questions were related to knowledge about folic acid, three questions assessed attitudes towards folic acid intake, one question assessed folic acid intake behaviour and a final question addressed the reasons for not taking folic acid. Among those eight questions on knowledge, four points were defined as core knowledge: the preventive role of folic acid, intake time, intake method and intake dose. In each county, one or two maternal and child healthcare workers received training as investigators responsible for participant recruitment and data collection. The formal investigation was conducted after obtaining the participants' consent.

The $\chi^{2}$ analysis was performed to test for the difference in the proportions of various characteristics between two or more groups. Logistic regression analysis was used for quantifying an association while adjusting for possible confounding factors.

\section{Results}

A total of 34626 women were recruited into the present survey. From the questionnaires obtained from the women, 1601 were excluded because of logical errors or incomplete content. Finally, 33025 questionnaires were used in the present study. The response rate was $95.4 \%$.

Of the 33025 women, $42 \%$ were within $25-30$ years of age and $72 \%$ were from urban areas. In terms of ethnicity, $72 \%$ were Han Chinese. In terms of educational level, $64 \%$ had attained educational levels below senior high school. In addition, $81 \%$ had an average annual income of $<6000$ RMB (equal to \$US 860) per person. Of all the respondents, a total of 18648 women had heard of folic acid, indicating that the awareness rate was only $57 \%$. In all, $12 \%$ took folic acid daily but only $8 \%$ took the recommended amount. Among the women with $>12$ weeks of gestation, $8 \%$ took folic acid 3 months before pregnancy and 3 months after conception. Furthermore, only $4 \%$ of non-pregnant women took folic acid (Table 1).

Folic acid awareness and intake behaviour were analysed in relation to different characteristics. The univariate analysis results from the $\chi^{2}$ test showed that all demographic characteristics seemed to influence folic acid awareness and intake behaviour; all $P$ values were $<0 \cdot 001$ (Table 1). We used the logistic regression analysis to quantify the association of demographic characteristics on awareness and intake behaviour while adjusting for possible confounding factors. Urban residence was positively associated with women's folic acid awareness $(\mathrm{OR}=1 \cdot 41)$, and women's pregnant status was a significant factor for awareness (OR $=1 \cdot 51)$. The increase in educational level was associated with an increase in awareness rate; however, annual income had a weak impact on awareness (Table 2).

With regard to intake behaviour, the dominant factor was women's pregnant status $(\mathrm{OR}=4 \cdot 878)$, and the rate increased with an increase in educational level (Table 2). No significant differences in intake behaviour were found between women from urban and rural areas $(P=0 \cdot 091)$.

Knowledge about folic acid was further analysed according to the following indicators: $44 \%$ of participants knew that folic acid was a type of vitamin and $27 \%$ were aware of the recommended daily folic acid dose, which was relatively low. In all, $15 \%$ of women were familiar with all core knowledge of folic acid, which had the lowest rate among all indicators.

The intake rates among women who had partial knowledge of folic acid were lower than among those who had core knowledge. The intake rates in the two groups were $16 \%$ and $42 \%$, respectively. In addition, the difference between the intake rates of the two groups was significant $(P<0 \cdot 001)$.

The main source of folic acid knowledge for the participants (57\%) was doctors (Table 3). About 34\% of women received knowledge from mass media sources 
Table 1 Association of folic acid awareness and intake behaviour with different demographic characteristics in six provinces of China, 2008

\begin{tabular}{|c|c|c|c|c|c|c|c|c|}
\hline \multirow[b]{2}{*}{ Characteristic } & \multicolumn{2}{|c|}{ Survey sample } & \multicolumn{3}{|c|}{ Heard of folic acid } & \multicolumn{3}{|c|}{ Folic acid intake } \\
\hline & $n$ & $\%$ & $n$ & Rate (\%) & $P$ value* & $n$ & Rate (\%) & $P$ value \\
\hline \multicolumn{9}{|l|}{ Residence } \\
\hline Urban & 9322 & $28 \cdot 2$ & 6804 & $73 \cdot 0$ & \multirow[t]{2}{*}{$<0.01$} & 976 & $10 \cdot 5$ & \multirow[t]{2}{*}{$<0.01$} \\
\hline Rural & 23703 & $71 \cdot \overline{8}$ & 11844 & $50 \cdot 0$ & & 1801 & $7 \cdot 6$ & \\
\hline \multicolumn{9}{|l|}{ Ethnic groups } \\
\hline Han & 23873 & $72 \cdot 3$ & 15215 & $63 \cdot 7$ & \multirow{2}{*}{$<0.01$} & 2276 & $9 \cdot 5$ & \multirow{2}{*}{$<0.01$} \\
\hline Others & 9152 & $27 \cdot 7$ & 3433 & $37 \cdot 5$ & & 501 & $5 \cdot 5$ & \\
\hline \multicolumn{9}{|l|}{ Educational level } \\
\hline Illiterate & 1686 & $5 \cdot 1$ & 459 & $27 \cdot 2$ & \multirow{6}{*}{$<0.01$} & 46 & $2 \cdot 7$ & \multirow[t]{6}{*}{$<0.01$} \\
\hline Primary school & 5552 & $16 \cdot 8$ & 2027 & $36 \cdot 5$ & & 255 & $4 \cdot 6$ & \\
\hline Junior high school & 13828 & $41 \cdot 9$ & 7108 & $51 \cdot 4$ & & 1101 & $8 \cdot 0$ & \\
\hline Senior high school & 7077 & $21 \cdot 4$ & 5059 & $71 \cdot 5$ & & 776 & $11 \cdot 0$ & \\
\hline Junior college & 3834 & $11 \cdot 6$ & 3157 & $82 \cdot 3$ & & 465 & $12 \cdot 1$ & \\
\hline University degree and above & 1048 & $3 \cdot 2$ & 838 & $80 \cdot 0$ & & 134 & $12 \cdot 8$ & \\
\hline \multicolumn{9}{|c|}{ Average annual income per person (RMB) } \\
\hline$<1500$ & 11240 & $34 \cdot 0$ & 5449 & $48 \cdot 5$ & \multirow[t]{5}{*}{$<0.01$} & 732 & $6 \cdot 5$ & \multirow[t]{5}{*}{$<0.01$} \\
\hline 1500-2999 & 9380 & $28 \cdot 4$ & 5233 & $55 \cdot 8$ & & 839 & $8 \cdot 9$ & \\
\hline 3000-5999 & 6282 & $19 \cdot 0$ & 3779 & $60 \cdot 2$ & & 571 & $9 \cdot 1$ & \\
\hline $6000-10000$ & 3533 & $10 \cdot 7$ & 2376 & $67 \cdot 3$ & & 340 & $9 \cdot 6$ & \\
\hline$>10000$ & 2590 & $7 \cdot 8$ & 1811 & $69 \cdot 9$ & & 295 & $11 \cdot 4$ & \\
\hline \multicolumn{9}{|l|}{ Pregnancy } \\
\hline Non-pregnancy & 22345 & $67 \cdot 7$ & 12115 & $54 \cdot 2$ & \multirow[t]{2}{*}{$<0.01$} & 956 & $4 \cdot 3$ & \multirow[t]{2}{*}{$<0.01$} \\
\hline Pregnancy & 10680 & $32 \cdot 3$ & 6533 & $61 \cdot 2$ & & 1821 & $17 \cdot 1$ & \\
\hline
\end{tabular}

${ }^{*}$ Calculated from the $\chi^{2}$ test.

Table 2 Adjusted association of folic acid awareness and intake behaviour with different demographic characteristics in six provinces of China, 2008*

\begin{tabular}{|c|c|c|c|c|}
\hline \multirow[b]{2}{*}{ Characteristic } & \multicolumn{2}{|c|}{ Heard of folic acid } & \multicolumn{2}{|c|}{ Folic acid intake } \\
\hline & OR & $95 \% \mathrm{Cl}$ & OR & $95 \% \mathrm{Cl}$ \\
\hline Urban residence & $1 \cdot 41$ & $1 \cdot 33,1 \cdot 50$ & 1.09 & $0.99,1.20$ \\
\hline Han ethnicity & $2 \cdot 65$ & $2 \cdot 51,2 \cdot 79$ & $1 \cdot 67$ & $1.51,1.85$ \\
\hline \multicolumn{5}{|l|}{ Educational level } \\
\hline Illiterate & \multicolumn{2}{|c|}{ Reference } & \multicolumn{2}{|c|}{ Reference } \\
\hline Primary school & $1 \cdot 29$ & $1 \cdot 14,1 \cdot 47$ & $1 \cdot 50$ & $1 \cdot 09,2 \cdot 07$ \\
\hline Junior high school & $2 \cdot 20$ & $1 \cdot 96,2 \cdot 47$ & $2 \cdot 60$ & $1.92,3.52$ \\
\hline Senior high school & $4 \cdot 70$ & $4 \cdot 15,5 \cdot 33$ & $3 \cdot 76$ & $2 \cdot 76,5 \cdot 13$ \\
\hline Junior college & $8 \cdot 07$ & $6 \cdot 97,9 \cdot 35$ & $4 \cdot 28$ & $3 \cdot 10,5 \cdot 91$ \\
\hline University degree and above & $7 \cdot 07$ & $5 \cdot 80,8 \cdot 61$ & $4 \cdot 41$ & $3 \cdot 07,6 \cdot 34$ \\
\hline \multicolumn{5}{|c|}{ Average annual income per person (RMB) } \\
\hline$<1500$ & \multicolumn{2}{|c|}{ Reference } & \multicolumn{2}{|c|}{ Reference } \\
\hline 1500-2999 & 1.08 & $1 \cdot 02,1 \cdot 15$ & $1 \cdot 21$ & $1 \cdot 08,1 \cdot 34$ \\
\hline $3000-5999$ & $1 \cdot 08$ & $1 \cdot 01,1 \cdot 16$ & $1 \cdot 07$ & $0.95,1.20$ \\
\hline $6000-10000$ & 1.08 & $0 \cdot 99,1 \cdot 18$ & $1 \cdot 06$ & $0.92,1.23$ \\
\hline$>10000$ & $1 \cdot 06$ & $0.96,1 \cdot 18$ & $1 \cdot 19$ & $1 \cdot 02,1.39$ \\
\hline Being pregnant & 1.51 & $1 \cdot 44,1.59$ & $4 \cdot 88$ & $4 \cdot 49,5 \cdot 30$ \\
\hline
\end{tabular}

${ }^{*}$ Calculated from the logistic regression analysis.

such as television, radio, newspapers, magazines and books. Moreover, we found that the group of women who obtained knowledge from family planning staff had the highest daily intake rate (33\%).

Among women who did not take folic acid, 49\% were not familiar with folic acid and were not aware of the importance of taking it (Table 4). Some participants did not take folic acid because of misconceptions about it. For example, 13\% believed that folic acid was a drug and should not be taken by a healthy woman; $11 \%$ thought that they had eaten enough green leafy vegetables and had no need to take additional folic acid and $6 \%$ did not take folic acid because of economic limitations.

\section{Discussion}

Measuring folic acid awareness and intake rates among women of childbearing age is essential for understanding the effect of folic acid intervention on NTD. This understanding is important while planning folic acid intervention programmes. The results from the China-US Collaborative 
Table 3 Sources of knowledge related to folic acid in six provinces of China, 2008

\begin{tabular}{lcc}
\hline Sources & $n$ & $\begin{array}{c}\text { Daily intake } \\
\text { rate (\%) }\end{array}$ \\
\hline Doctor & 10691 & $26 \cdot 1$ \\
Relatives/friends & 4367 & $23 \cdot 2$ \\
Television/radio/newspaper/ & 6284 & $21 \cdot 8$ \\
$\quad$ magazine/books & & \\
Staff of family planning & 3628 & $33 \cdot 2$ \\
Others & 627 & $22 \cdot 0$ \\
\hline
\end{tabular}

Table 4 Reasons for not taking folic acid in six provinces of China, 2008

\begin{tabular}{lcc}
\hline Reasons & $n$ & Rate (\%) \\
\hline $\begin{array}{l}\text { Does not know she should take folic } \\
\quad \text { acid/have not heard of folic acid }\end{array}$ & 12932 & $48 \cdot 9$ \\
Thinks folic acid is a drug & 3451 & $13 \cdot 0$ \\
Eats enough green leafy vegetables and & 2819 & $10 \cdot 7$ \\
$\quad$ does not need to take additional folic acid & & \\
Does not know the benefits of folic acid & 2491 & $9 \cdot 4$ \\
Folic acid is too expensive & 1667 & $6 \cdot 3$ \\
Folic acid is not recommended by the doctor & 1639 & $6 \cdot 2$ \\
Forgets to take folic acid & 1631 & $6 \cdot 2$ \\
Others & 3418 & $3 \cdot 8$ \\
\hline
\end{tabular}

Project for Neural Tube Defect Prevention showed the effectiveness of daily supplementation of $400 \mu \mathrm{g}$ of folic acid among women preparing for pregnancy in the Chinese population. Since then, the folic acid supplementation measures had been promoted through some local agencies, such as a family planning department and a civil affairs department. However, in 2008 the government of China began to provide folic acid free of charge to women of reproductive age in 293 low-income counties of six provinces with a high prevalence of NTD. The present survey was the baseline investigation before intervention programmes began. One year later, the Chinese government expanded the intervention from 293 counties of six provinces to all rural areas of China on the basis of the results of the present study.

Many studies on folic acid awareness and intake rates have been conducted in different counties, areas and populations. Some of these studies have measured folic acid awareness rates, such as the rate of exposure to information about folic acid or that folic acid prevents NTD, or the rate of folic acid supplementation before pregnancy. Such rates appear high in many of the countries studied. About $95 \%$ of respondents in Canada in 2003 were aware of folic acid ${ }^{(19)}$, nearly $77 \%$ of women in Australia had heard of folic acid ${ }^{(20)}$ and about $84 \%$ of women in the USA knew about folic acid ${ }^{(21)}$. However, knowledge about the preventive role of folic acid and folic acid supplementation methods was found to be much lower than general awareness about folic acid. For example, a study conducted in South Australia in 2007 indicated that only $39 \%$ of subjects were aware that they should take folic acid before pregnancy ${ }^{(20)}$. In another study conducted in 2008 , only $39 \%$ of surveyed women in the $\mathrm{USA}^{(21)}$ and $25 \%$ of those surveyed in Canada ${ }^{(19)}$ were aware that folic acid can prevent NTD.

From the results of the logistic analysis, we found that the awareness rate among women was related to residence, ethnicity, educational level and pregnancy status. The intake behaviour was associated with ethnicity, educational level and pregnancy status. The average increase of annual income per person did not necessarily influence women's awareness and intake behaviours. It indicated that women's educational level was an important factor for awareness and intake behaviour; hence, more programmes should be designed for women with low educational levels, as well as for non-pregnant and minority women. Meanwhile, considering the residence factor, more folic acid information channels should be found for women living in remote areas.

Moreover, we also found that the intake rate correlated with whether women had core knowledge of folic acid. Only $15 \%$ of women in our study were familiar with all of the core information about folic acid, which was remarkably lower than the rate of those who had only certain knowledge points about folic acid. By contrast, this group had a significantly higher intake rate than other groups who had only partial knowledge about folic acid, indicating that women who had core knowledge are more easily persuaded to take folic acid compared with others. Therefore, although most women had heard of folic acid, only few were aware of the core points of knowledge for folic acid supplementation. Normally, it is rational to assume that the higher the awareness rate, the higher the intake rate. However, the ideal situation was not seen in many reports. For example, in the USA, the rate of those who had heard of folic acid was nearly $80 \%$ but the intake rate was about $40 \%$, and our study showed similar results. We speculated that just hearing of folic acid was not enough for women to change their behaviour. Therefore, we suggested that the awareness promotion should emphasise on the core knowledge of folic acid supplementation. In addition, the core knowledge should be considered as the awareness indicator. It possibly contributes to improvement in health education.

Many studies have reported intake rates and trends in many counties. In the UK, $44.6 \%$ of surveyed pregnant women took folic acid in $1998^{(22)}$; of the women surveyed in the USA, 28\% were reported to take folic acid in 1995 , which increased to $33 \%$ in $2005^{(12)}$ and to $40 \%$ in $2007^{(21)}$. In a study conducted in Japan in 2002, only $9 \cdot 1 \%$ of surveyed pregnant women took folic acid, which increased to $43 \cdot 1 \%$ in $2007^{(14)}$. A survey of small samples in the northern areas of China with a high prevalence of NTD showed that the folic acid intake rate was $10 \cdot 2 \%$ in $2005^{(17)}$, whereas the intake rate among pregnant women was $15 \%$ in $2004^{(23)}$. In the present survey, the intake rate was $12 \%$ in the northern areas of China with a high prevalence of NTD in 2008. Although there were different samples for 
both studies, the findings suggested no remarkable changes during these years. Moreover, still fewer participants took folic acid before pregnancy. The intake rate in China as of 2008 was similar to that of most developed countries in 2000. We identified a significant gap in folic acid intake for women in poor Chinese areas with a high prevalence of NTD compared with those in developed countries. Thus, this gap became a priority intervention field for folic acid supplementation. More efficient interventions are required to encourage women to take folic acid.

Because many women were not taking folic acid, understanding the reasons behind their decision was indispensable. Previous studies rarely analysed why women did not take folic acid, except for the reports from March of Dimes. Our study also focused on some details of cause analysis. The results showed that $49 \%$ of participants had never heard of folic acid, which is the first main cause. Various misconceptions on folic acid supplementation became the succeeding reasons why women did not take folic acid. These findings indicated that educational materials should list not only the benefits of folic acid but also women's misconceptions about supplementation. Among those who did not take folic acid, 6\% said that the reason was purely economical. Therefore, the economic factor is not a major reason behind the decision not to take folic acid.

Our results showed that doctors' recommendations affected women's decisions to take folic acid, which supports the results of other studies. For example, a study conducted in Chile found that about $54 \%$ of surveyed individuals obtained information on folic acid through midwives and doctors ${ }^{(24)}$. Some special training should aim at enhancing health practitioners' knowledge about folic acid and promote their counselling skills.

\section{Conclusion}

In general, there was a large gap in folic acid supplementation awareness and intake rates between China and developed countries in 2008. Meanwhile, the present study found that core knowledge about folic acid supplementation is essential for improving the folic acid intake rate. More knowledge points should be provided for women as the next step in our folic acid promotion programme. Our results suggest that future policies must focus on women with low educational levels living in remote areas who hold misconceptions about folic acid supplementation. Meanwhile, doctors and health practitioners should also play an influential role in changing women's attitudes towards folic acid and its intake.

\section{Acknowledgements}

The present survey was supported by the National Key Project of Scientific and Technical Supporting Programs (2008-2010) of China: National Project for Child Birth
Defects Prevention, Code 2006BAI05A01. The authors have no conflict of interest to declare. J.Z. developed the study and revised the draft; X.M. was responsible for field investigation; Z.Z. conducted all analyses and drafted the writing; Y.W. and P.Y. helped to conceptualise ideas and review drafts of the article. The authors thank the maternal and child health doctors in hospitals of six provinces for their assistance in the present survey.

\section{References}

1. Lumley J, Watson L, Watson M et al. (2001) Periconceptional supplementation with folate and/or multivitamins for preventing neural tube defects. Cochrane Database Syst Rev, issue 3, CD001056. http://www2.cochrane.org/ reviews/en/ab001056.html

2. Johansson M, Witthöft CM, Bruce A et al. (2002) Study of wheat breakfast rolls fortified with folic acid. The effect on folate status in women during a 3-month intervention. Eur J Nutr 41, 279-286.

3. Wilson RD, Johnson JA, Wyatt P et al. (2007) Pre-conceptional vitamin/folic acid supplementation 2007: the use of folic acid in combination with a multivitamin supplement for the prevention of neural tube defects and other congenital anomalies. J Obstet Gynaecol Can 29, 1003-1026.

4. Tamin H, Hanison G, Atoui M et al. (2009) Preconceptional folic acid supplement use in Lebanon. Public Health Nutr 12, 687-692.

5. Hertrampf E \& Cortes F (2008) National food-fortification program with folic acid in Chile. Food Nutr Bull 29, Suppl. 2, S231-S237.

6. De Wals P, Tairou F, Van Allen ML et al. (2007) Reduction in neural tube defects after folic acid fortification in Canada. New Engl J Med 357, 135-142.

7. Honein A, Paulozzi LJ, Marthews TJ et al. (2001) Impact of folic acid fortification of the US food supply on the occurrence of neural tube defects. JAMA 285, 2981-2986.

8. Shakur YA, Rogenstein C, Hartman-Craven B et al. (2009) How much folate is in Canadian fortified products 10 years after mandated fortification. Can J Public Health 100, 281-284.

9. Allen L, de Benoist B, Dary O et al. (2006) Guidelines on Food Fortification with Micronutrients. Geneva: WHO; available at http://whqlibdoc.who.int/publications/2006/ 9241594012_eng.pdf

10. Kari JA, Bardisi ES, Baitalmal RM et al. (2008) Folic acid awareness among female college students: neural tube defects prevention. Saudi Med J 29, 1749-1751.

11. Nawapun K \& Phupong V (2007) Awareness of the benefits of folic acid and prevalence of the use of folic acid supplements to prevent neural tube defects among Thai women. Arch Gynecol Obstet 276, 53-57.

12. Coll O, Pisa S, Palacio M et al. (2004) Awareness of the use of folic acid to prevent neural tube defects in a Mediterranean area. Eur J Obstet Gynecol Reprod Biol 115, 173-177.

13. Green-Raleigh K, Carter H, Mulinare J et al. (2006) Trends in folic acid awareness and behavior in the United States: the Gallup Organization for the March of Dimes Foundation survey, 1995-2005. Matern Child Health J 10, Suppl. 5, S177-S182.

14. Kondo A, Yamamoto S, Inoue H et al. (2009) Folic acid in the prevention of neural tube defects: awareness among laywomen and healthcare providers in Japan. Congenit Anom (Kyoto) 49, 97-101.

15. Moore CA, Li S, Li Z et al. (1997) Elevated rates of severe neural tube defects in a high-prevalence area in northern China. Am J Med Genet 73, 113-118.

16. Frey L \& Hauser WA (2003) Epidemiology of neural tube defects. Epilepsia 44, Suppl. 3, S4-S13. 
17. Zhang L, Ren A, Li Z et al. (2006) Folate concentrations and folic acid supplementation among women in their first trimester of pregnancy in a rural area with a high prevalence of neural tube defects in Shanxi, China. Birth Defects Res A Clin Mol Teratol 76, 461-466.

18. Li Z, Ren A, Zhang L et al. (2007) Periconceptional use of folic acid in Shanxi province of northern China. Public Health Nutr 10, 471-476.

19. French MR, Barr SI \& Milne RL (2003) Folate intake and awareness of folate to prevent neural tube defects: a survey of women living in Vancouver, Canada. J Am Diet Assoc 103, 181-185.

20. Chan AC, van Essen P, Scott $\mathrm{H}$ et al. (2008) Folate awareness and the prevalence of neural tube defects in South Australia, 1966-2007. Med J Aust 189, 566-569.

21. March of Dimes Foundation (2008) Improving Preconception Health: Women's Knowledge and Use of Folic Acid.
White Plains, NY: March of Dimes Foundation; available at http://www.marchofdimes.com/peristats/pdfdocs/2008folicacid surveyreport.pdf

22. Sen S, Manzoor A, Deviasumathy M et al. (2004) Maternal knowledge, attitude and practice regarding folic acid intake during the periconceptional period. Public Health Nutr $\mathbf{4}$, 909-912.

23. Ren A, Zhang L, Li Z et al. (2006) Awareness and use of folic acid, and blood folate concentrations among pregnant women in northern China - an area with a high prevalence of neural tube defects. Reprod Toxicol 22, 431-436.

24. Pardo VRA, Lay-Son RG, Aranda Ch W et al. (2007) Awareness and knowledge of the use of folic acid in the prevention of neural tube defects: a survey of women living in Santiago, Chile. Rev Med Chil 135, 1551-1557. 